\title{
Article
}

\section{The Flemish Interactive Coaching Monitoring System}

Ponnet, Hans, Vangrunderbeek, Hans and Mccarthy, Liam

Available at http://clok.uclan.ac.uk/36594/

Ponnet, Hans, Vangrunderbeek, Hans and Mccarthy, Liam ORCID: 0000-00018067-1629 (2021) The Flemish Interactive Coaching Monitoring System. International Sport Coaching Journal . pp. 1-10. ISSN 2328-918X

It is advisable to refer to the publisher's version if you intend to cite from the work. http://dx.doi.org/10.1123/iscj.2020-0093

For more information about UCLan's research in this area go to http://www.uclan.ac.uk/researchgroups/ and search for < name of research Group>.

For information about Research generally at UCLan please go to http://www.uclan.ac.uk/research/

All outputs in CLoK are protected by Intellectual Property Rights law, including Copyright law. Copyright, IPR and Moral Rights for the works on this site are retained by the individual authors and/or other copyright owners. Terms and conditions for use of this material are defined in the policies page.

\section{CLoK}

Central Lancashire online Knowledge www.clok.uclan.ac.uk

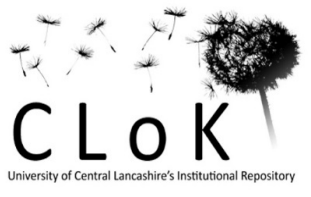


6

7

8

Date of submission: October 13, 2020

9 


\section{Abstract}

As large-scale coach education programmes receive a growing amount of attention and investment (e.g., human and financial resource), the case for increased understanding of their impact is a pressing matter. In this paper, we outline the creation of the Flemish Interactive Coaching Monitoring System (FICOMS) within the Flemish School for Coach Education (Belgium). FICOMS is a data warehouse consisting of multiple databases, which was set up in 2019 to integrate data on coach education and coach certifications (1960-present), active coaches within club-organised sports (2014-present) and sport clubs, sports participants and sports infrastructure. FICOMS provides a variety of interactive and externally facing dashboards with useful statistics on coach education and coaching in Flanders. For example, the evolution of drop out ratios of qualified versus non-qualified coaches in sports clubs and sports federations can be identified, as well as the evolution of the percentage of qualified coaches in a specific sport, sports federation, gender or regional differences. By describing the main characteristics of FICOMS and sharing some emerging insight and early possibilities, we aim to clarify the potential of this information technology for different stakeholders, such as governments, policymakers, sports federations, Olympic committees, education partners, municipalities and researchers.

Keywords: benchmarking, coach education, evaluation, monitoring, sports coaching, sports policy 


\section{The Flemish Interactive Coaching Monitoring System (FICOMS)}

Coaches are central to both promoting sport within society and contributing to the development of healthy and active populations (Erickson, Bruner, MacDonald \& Côté, 2008).

Not only are coaches concerned with improving the athletic performance of individuals and teams (Cushion, Armour and Jones, 2003), but also enhancing the personal well-being of those who take part in sport (European Commission, 2020). As such, the role of the coach should not be understated. Not simply because of the vast scope of their role, but also because of the significant scale of the 'coaching workforce'. According to the International Council for Coaching Excellence (2013), sports coaching occurs in nearly 200 countries, is delivered by millions of coaches and received by an even greater number of participants. At a more local level, according to a report by Lara-Bercial et al. (2017), it is suggested that in the European Union (EU) alone, up to 9 million coaches are delivering sport to more than one hundred million participants across all twenty-eight member states. To offer a comparison, the EU is home to close to 6 million teachers, 1.6 million doctors and 1.6 million police officers (Eurostat, 2019). Consequently, it can be argued that sports coaches are one of Europe's largest workforces (European Commission, 2020).

Indeed, we support the argument made by others that while global interest in sports coaching has never been higher, high-quality sports coaching is a shared international concern (Callary \& Gearity, 2019; International Council for Coaching Excellence, 2013). In direct response to this concern, there has been an increase in the development of large-scale coach education programmes worldwide, which seek to improve the quality of sports coaching (Duffy et al, 2011). Although much of this early pioneering work was undertaken in Canada, Australia and the UK during the 1990s, countries continue to develop their coach education programmes and frameworks around the globe (Duffy et al, 2011; Campbell \& Waller, 2020). For example, in South Africa "more emphasis is being placed on the quality of coaching 
through a proposed standardised series of qualifications" (Coopoo \& Morris-Eyton, 2014, p.

3). Going further, coach education in South Africa "is being foregrounded by the implementation of the South African Coaching Framework" (Morris-Eyton \& Roux, 2019, p.

87). Meanwhile in Brazil, where sports coaching is a recognised professional activity (Ciampolini et al, 2020, Milistetd et al, 2016), the majority of coaches are required to be educated to degree level in a relevant subject (e.g., physical education) by law (Galatti et al, 2016). Finally, much more insight can be found within the International Sports Coaching Journal 'Coaching in...' section; a burgeoning body of work which reflects the breadth and depth of sports coaching activity around the globe. We have provided a brief summary of this work in Table 1, which can be found below.

However, despite what appears to be a colossal amount of resource (i.e., financial and human) invested into the design and development of coach education frameworks, little attention has been paid to meaningful long-term monitoring and evaluation within this field. By that, we mean evidence of a coherent and comprehensive monitoring and evaluation system which accounts for input (i.e., coaches entering programmes), throughput (i.e., characteristics of those programmes) and output (i.e., sports coaching activity, coach drop out) over time. Instead, coach education researchers have spent much time investigating single programme-level issues including how coaches learn (Mallett, Trudel, Lyle \& Rynne, 2009; Stodter \& Cushion, 2017) and how coaches experience coach education (Piggott, 2012). While this is undoubtedly beneficial (for example, this research has been translated into guidelines to make improvements to specific programmes), we argue that the paucity of research concerned with the monitoring and evaluation of coach education frameworks is an issue. Yet, to our knowledge only a limited amount of this type of work has been undertaken (e.g., Estonian Foundation of Sports Education and Information, 2020; sports coach UK, 2009). While policymakers and researchers mostly have a clear view on the quantities and 
characteristics of coaches entering coach education programmes (i.e., input), successfully completing these programmes and obtaining qualifications (i.e., throughput), few up-to-date monitoring and evaluation systems are available to understand (for example) who is actively coaching within the field and where (i.e., output). Methods used are most commonly surveys, providing only a limited response to such questions at one specific snapshot in time (Santos et al, 2019).

While we have made the case for the significance of sports coaching, the growth in education programmes to support coaches and the considerable resource implications of this work, central to our argument is that insights generated from monitoring and evaluation work has great utility for a wide variety of sports coaching stakeholders. For example, where organisations operate at an international level there is an opportunity for benchmarking (see: North, 2016). For regional or local organisations, the data presents an opportunity to understand which coaches are required where and what type of support should be provided for whom. This type of work is not new and exists or is well developed within other sectors. One closely related sector is sports participation, where monitoring and evaluation is commonplace, carried out in sophisticated ways for a variety of purposes (e.g., Cushman, Veal \& Zuzanek, 2005; Gratton, Rowe \& Veal, 2011). In the UK “NGBs 'earn autonomy’ (and increased public funding) through the creation of 'Whole Sport Plans' which are subject to biannual review and ongoing monitoring and evaluation” (Piggott, 2012, p. 537).

Monitoring and evaluation is also the norm within international sport for development settings, specifically as a means of developing evidence of 'what works' in "a field defined by its claims as opposed to its results" (Harris, 2018, p. 796). It would seem that parallels could be drawn here with the field of coach education. As such, within the present paper we wish to not only advance calls for the type of work to be carried out, but also showcase The Flemish Interactive Coaching Monitoring System (FICOMS). In doing this, we will demonstrate how 
the long-term monitoring and evaluation of coach education and its impact in the field of sports coaching in Flanders is both unique, has utility and can have wide-ranging impact among a variety of sports coaching stakeholders (e.g., policymakers, sports federations and local municipalities).

information, including pre-existing standalone databases, together into a single data warehouse. The main databases and the most important connections between them are illustrated in figure 1 . The relationship between the different databases makes it possible to monitor which coaches are active within club-organised sports in Flanders on a yearly basis (data from 2014-2019) including the sports clubs or sports infrastructures with active coaches. FICOMS also makes it possible to establish relationships between characteristics of coaches and sports participation (data from 2014-2019). Since the Flemish School for Coach Education (VTS) is responsible for coach education in Flanders (Vangrunderbeek \& Ponnet, 2020), FICOMS gives full insight in relation to coaches obtaining new qualifications (data from 1960-present) and the content of coach education programmes (data from 2010-present).

Within the present section, we intend to describe how the complex background structure of FICOMS has been set up by linking four different databases in a data warehouse and then adding three layers to it to make it possible for creating user-friendly dashboards.

Firstly, the database SportsDB contains more than 28,000 sports clubs and sports federations in Flanders (https://www.sport.vlaanderen/waar-sporten/vind-eensportorganisatie/). This is always up to date, in real time, and contains a unique ID for each and every sports club, name, abbreviation, legal form, date of incorporation, contact details, address(es), phone, e-mail, website, social media, sports infrastructures that are used, sports and disciplines, links/relations with other organisations (e.g., sports federations on Flemish, 
Belgian, European or international level or sports services in the municipalities), target groups, creation and modification dates, and much more.

Secondly, the database Spakki, contains data related to more than 22,500 sports infrastructures (https://www.sport.vlaanderen/waar-sporten/vind-je-sportplaats/). The database is always up to date, in real time, and similarly contains a unique ID for every sports infrastructure, name, type of sports infrastructure, owner, website, address, location in a sports domain (group of sports infrastructures), usage (schools, groups, individuals), surface, width and height (or number of lanes, perimeter, etc.), sports clubs that use the sports infrastructure, specific features (e.g., toilet, shower, parking, lighting), creation and modification dates, etc.

Links between sports clubs, sports federations, sports and sports infrastructures can be drawn by linking both databases listed above. Next, linking coaches with sports clubs, sports federations, sports or sports infrastructures, a third database (CoachDB, not publicly available) was set up in 2013. For sports federations it became mandatory that same year (by a decree on the recognition and subsidisation of sports federations) to give a complete digital overview of all their active coaches on a yearly basis. The data on the coaches contains personal details (name, surname, address, birth date, gender) for checks in the subsidisation process, but was anonymised after processing and before uploading in the database where every person is allocated a unique but encrypted ID. Besides the remaining data on gender, age and residence, every coach (by its ID) is linked to one or more sports clubs, one or more sports federations, one or more sports and possesses either no qualification, a Physical Education (PE) qualification, a qualification from VTS or a combination of both.

At this point, a fourth database, 'Vlaams Opleidingen voor Trainers Administratie Systeem' (VOTAS) (https://www.sport.vlaanderen/vts), plays an essential role. VOTAS is the database of the Flemish government, managed by VTS, which contains every coach qualification obtained since 1956 and every PE-qualification since 2008. Although not 
systematic, also many PE qualifications before 2008 are registered in the database. In the work of Vangrunderbeek \& Ponnet (2020), different pathways for obtaining a qualification are described, such as pathways for former elite athletes. Indeed, VOTAS contains a lot more information than simply qualifications. Every coach education programme (with details on modules, items, hours) and coaching course in Flanders is registered in the database, every coach has to enrol for the course, grades are given by our coach developers through the system, etc. Each sports federation has to list a unique VOTAS-ID for every qualified coach and during the subsidisation process this information is checked and altered if necessary, before uploading this information to the CoachDB. By combining VOTAS and CoachDB, it is possible to know which coaches are qualified in what sport or sports federation, the percentage of qualified coaches in each sport, which gender, age or regional differences exist, etc.

The complex structure in the background of FICOMS is described in the above paragraphs. The real strength of FICOMS, we argue, is how complex information is translated into easily understandable, interactive dashboards (foreground) with useful insights and statistics on coaching in Flanders. As such, we have created a system (figure 2) with three layers (data store, data model, data visualisation tool). The data store is developed to store the data and perform calculations on the data. The data model is created for making relations between dimensions and facts (calculations from data store). The data store and data model refreshes automatically each day, so every calculation (and visualisation) on the data is automatically updated. For data visualisation, Microsoft Power BI Pro and Embedded functionality is used, because of the integration with other existing systems, possibilities (bookmarks, export of data), visuals, design and ease of use. Our data and visualisations are presented in layers to the many different users. The first layer is non-secure and shows publicly available information to interested citizens, policymakers and researchers who want a 
general overview. The second level is a secure, non-public layer which is accessible for policymakers at municipality level or sports federation level, but is also a layer for in-depth policy (e.g., Sport Vlaanderen, Minister for Sport, parliament). Data are anonymised for all layers to be compliant with the General Data Protection Regulations (GDPR). It is worth noting that all dashboards are interactive. For example, when one page on the dashboard represents the number of active coaches on a yearly basis between 2014 and 2019, data filters are added to that page so that a user can filter on gender, age category, qualified vs. nonqualified, region, sport, sports federation, and each combination. This means that with one page on a dashboard, a user can have dozens of graphs with very specific and tailored information.

FICOMS has been developed to monitor input, throughput and output of coaching in Flanders (figure 3) so that policymakers can intervene quickly when performance indicators change. With regard to input, there is permanent monitoring of the background (i.e., age, gender, residence, sport, sports club, sports federation, PE-background) of coaches starting a coach education programme and the different pathways that coaches follow in their coach education (Vangrunderbeek \& Ponnet, 2020). FICOMS is installed to also monitor the throughput, meaning the characteristics of coach education programmes (i.e., modules, items, hours, success ratios) and coach developers (i.e., age, gender, residence, courses, theory vs. practice hours), monitoring differences between sports and benchmarking the coach education programmes with other countries. A Holistic Quality Control (HQC) is set up to follow up on quality of courses, coach developers and exams. An important performance indicator for sport policy in Flanders is how many coaches obtain a new qualification every year, with trends over time, pathways or differences in gender, age, sports and regions. However, the most difficult part is monitoring the output. This includes the characteristics of active coaches within Flanders' sports clubs. For example: how many (qualified and non-qualified) coaches 
are there active and which trends are concerning? How many sports clubs do/don't have a qualified coach and are there differences between sports, sports federations, regions, gender, age, etc? How many new coaches start (new) or stop (drop-out) coaching every year? An example of a dashboard in English illustrating the possibilities of FICOMS can be found here: https://www.sport.vlaanderen/kennisplatform/thema-trainers/db-coaches-active-in-flandersbelgium/.

Before describing the setting up of an interactive coaching monitoring system in Flanders, we illustrated in the previous section that FICOMS - through its unique relationship between four complementary databases - is able to give insights in relation to more than just singular coach education programmes. We also highlighted the long-term monitoring and evaluation possibilities and its impact for the stakeholders (e.g. policymakers, sports federations and local municipalities) in the field of sports coaching in Flanders.

\section{How was FICOMS made possible?}

Coach education in Flanders has a long tradition (Vangrunderbeek \& Ponnet, 2020). However, until 2019, it was only possible to monitor the input and throughput (figure 3) of VTS and as such, understanding of coach education in Flanders was limited. Now, because of FICOMS, it is possible to arrive at detailed insights on the characteristics of our coach education programmes since 2010, the number of coaching courses since 1998, number of coaches following a course and obtaining a qualification since 1960, etc. Details about coaches following our courses, like their PE-background, previous qualifications, study results, geographical information, etc. only became visible progressively since 2010 . Structured data collection on active coaches in the sports clubs in Flanders started only in recent years. Before explaining the legal framework of the data collection and the methodology of data collection and data processing, it is important to note that everything started with traditional surveys of the sports clubs. 
In 2003, a significant conference on the 'status' of sports clubs in Flanders was organised by Sport Vlaanderen, the agency responsible for sports policy in Flanders under supervision of the Minister of Sport. Sport Vlaanderen wanted to gather insights from the sports clubs, sports participants, legal form of sports clubs, volunteers and active coaches. In preparation for the conference, a survey was sent out to 19,032 sports clubs, of which 1,480 responded, and to the sports services of the municipalities where the response rate was $305 / 308$ (or 99\%). One of the main results presented at the conference was that in 2003 only about $46 \%$ of the coaches of the sports clubs in the survey could be considered as qualified. It is important to note however, that mainly larger, more established sports clubs where only one sport is practiced, responded to the survey. The definition of a qualified coach was also not clear and consequently, some coaches may have been counted as qualified although they were not.

In 2012, a new large-scale survey was released to 15,272 active sports clubs in Flanders with similar but also more detailed questions than in 2003. The response was 1,749 sports clubs (11.45\%), a potential indication that the number of questions was too great and that this way of data collection had reached its limits. Due to more specific questions (better data collection) in this survey, the qualification percentage could be calculated more precise and was pinned at $40.22 \%$.

While analysing the results of this survey of 2012, policymakers reported a requirement for more precise data collection and more interactivity within the data. It was suggested that the survey method offered only a high-level overview of active coaches, qualification degree and sports clubs with active coaches. As such, it was not possible to zoom in on regional differences, differences between sports or sports federations, gender and age categories, in order to gather insights in the types of sports clubs with or without qualified coaches; for policymakers this is essential information. 
As a result, in 2013, a drastic change was made to the way in which data was collected, for example it became mandatory by law to all subsidised sports federations to give a full digital dataset of all active coaches and sports participants to Sport Vlaanderen once a year at a specific date. Sports federations were given the time to start collecting data in a structured way for every sports club which is affiliated to the sports federation. Consequently, the data from 2013 (as a transition year) is rejected for further analysis because the data quality was insufficient. Extra control mechanisms were inserted in the data collection process to improve data quality to the desired quality standards. Data from 2014 onwards match the data quality standards.

In the current law, applicable from 2017, two important modifications were made. Firstly, subsidised sports federations are rewarded financially for good data quality and a higher number of qualified coaches in relation with their qualification level. The same obligation of giving a full digital dataset of coaches and sports participants is imposed to the solely recognised (but not subsidised) sports federations since 2017. It is mandatory for sports federations to use a template (Microsoft Excel) for the digital dataset of sports participants and coaches, consisting of following data fields (columns): name and unique ID of the sports federation, unique ID of member (coach or sports participant), name, address, birth date, gender, unique ID or sports club (link with SportsDB and extra information, see previous section); sport, recreational or competitive sports participant or not sporting member, indication if the person is a coach. Only for the coaches in the dataset, an extra data field with the unique ID in VOTAS can be added. With this unique ID, the link with the VOTAS-database and the qualifications of the coach is established. It is not desirable for sports federations to provide us with the information on the qualifications of the coaches. Sport Vlaanderen (by VTS) owns the database with all the qualifications and it is preferable, because of control mechanisms in the subsidisation process and correctness of the data, that the qualifications are 
added to the dataset centrally. It is important to point out that a person can have multiple lines in the digital dataset, for example practicing or coaching more than one sport or being active in more than one sports club. However, when the total numbers of sports participants and active coaches in Flanders are counted, they are only counted once.

By law, Sport Vlaanderen is allowed to use personal data during the subsidisation process, but after checks and calculations directly related to the subsidisation process, data on coaches and sports participants is anonymised. This is carried out by way of a data cleaning and anonymisation process. In the time period (e.g., data from 2019) between delivering the dataset to Sport Vlaanderen (it is obliged for sports federations to do this no later than January 31,2020 ) and the end of the subsidisation process (June 30,2020), most of the work in the data cleaning process is year-over-year corrections where coaches from the previous year are matched with the same coach in the current year, within or between sports federations. This is a really important step because personal data is not uploaded (e.g., name, birthday, address) to CoachDB, but an encrypted unique key for every person (UniquePersonID) which cannot be traced back to personal data. During upload, birthdays are translated to year of birth and address is translated to a municipality. Data is anonymised but the number of unique coaches or sports participants can be counted, using calculations based on the UniquePersonID. A second major part of the data cleaning process is linking the information of CoachDB with VOTAS and adding the flag 'qualified' or 'non-qualified' for every coach and listing for every UniquePersonID the PE-qualification or VTS-qualification. Because this information is stored in different fields, information can be combined. By this subsidisation process, data cleaning and connections between the databases SportsDB, CoachDB and VOTAS, Sport Vlaanderen combines the data of all active coaches and their qualifications in more than 17,000 sports clubs affiliated with more than 70 sports federations, coaching in more than 100 sports and disciplines. Because it is mandatory, not a single sports federation has ever skipped a year and 
so longitudinal data is now available from 2014 to 2019. It is argued that this is a unique feature of the work.

Data quality and completeness is essential for both policy purposes and ongoing scientific analysis. A lot of effort has been invested in improving data quality over the last years, this includes: providing a template file, data improvement by sports federations, feedback on data problems encountered by Sport Vlaanderen to the sports federations, huge investments in data cleaning by Sport Vlaanderen, and modifications in the subsidisation process to reward sports federations for better data quality. Problems cannot be completely avoided considering the volume of coaches or sports participants, but error margins are monitored annually and interventions are made if necessary. Due to this, the data is considered reliable, yet it should be noted that it has taken a period of eight years to achieve this. Equally, over that period of time, it has become clear that sports federations require reward for their efforts in contributing to a clean and comprehensive dataset. Consequently, interactive dashboards are offered to sports federations at no-cost and have been used by them to develop their own internal policy. Collaborating in this way to bring about desirable outcomes for all stakeholders is seen as a win-win situation.

As explained in the above paragraphs, FICOMS is located against the unique backdrop of Flanders and it is often many of the features of this context (e.g., the law) which make it work. However, we argue that there is much to learn about the principles of FICOMS and suggest that similar effective monitoring and evaluation systems can be designed elsewhere with similar results. The focus of the following section is to demonstrate emerging insight and early possibilities of FICOMS by presenting a number of very brief introductory case studies (CS) around specific areas of work. For example, the number of coaches obtaining qualifications (CS1), bridging the gap between qualified and non-qualified coaches in sports clubs (CS2) and finally, the drop out of coaches from sports coaching roles (CS3). 


\section{Emerging Insight from FICOMS}

Case study 1 (CS1) demonstrates that in 2019, more than 7,000 coaches entered one of the 230 coach education programmes of VTS. With a success rate of around $86 \%, 6,028$ of them obtained a VTS-qualification. The success rate is depending on the sports and level (Aspirant-Initiator to Trainer A). The current most popular sports in coach education are: soccer, tennis, gymnastics, horse riding, athletics, hockey, basketball, swimming and volleyball. Close to $64 \%$ of the coaches obtaining a qualification are male. The average age of coaches is almost 30 years but increases for the higher levels of coach education programmes (figure 4). The most popular pathway for obtaining a coach qualification is following a regular course under supervision of coach developers and with an exam and apprenticeship at the end of the course. Between 2015 and 2019, 26,326 coaches (89\% of all qualifications) chose this track, 13,820 following a coach education programme at the level of Initiator. Almost $11 \%$ of the coaches obtaining a VTS-qualification have a PE-qualification (Sport Vlaanderen, 2020).

Case study 2 (CS2), concerned with active coaches operating in sports clubs, illustrates that in 2019 only $8,234(<50 \%)$ of the 16,982 sports clubs affiliated with the sports federations have active coaches (https://www.sport.vlaanderen/kennisplatform/thema$\underline{\text { trainers/db-coaches-active-in-flanders-belgium/). In sports clubs of walking, recreational }}$ cycling or jogging and indoor soccer, it is clear that hardly any coaches are active. The number of sports clubs with coaches increased from 7,360 in 2014 to 8,234 in $2019(+11.9 \%)$ and the number of sports clubs with at least one qualified coach increased from 4,797 in 2014 to 5,699 in $2019(+18.8 \%)$. This is a positive evolution for quality at sports club level. To put this in perspective, organised sports participation in Flanders increased with 16.9\% from 2014 to 2019 (increase from $1,239,625$ to $1,448,514$ sports participants). The number of sports clubs with sports participants increased with $10.6 \%$ from 2014 to 2019. During recent years, it 
was often claimed in Flemish media that there is a lack of qualified coaches in Flanders (e.g., Decré, 2019; Le Bacq, 2019). FICOMS has been used to analyse the available data and identify an increase of $22.6 \%$ in active coaches and an increase of $37.5 \%$ in qualified coaches from 2014 to 2019 (figure 5). It has been difficult to measure exactly how much of an issue the lack of qualified coaches is. However, FICOMS revealed some insights how the gap is being partially closed due to a greater number of sports clubs with (qualified) coaches and the ratio of the amount of coaches versus amount of sports participants that increased from 0.0466 to $0.0489(+4.9 \%)$. Another parameter which is monitored closely through FICOMS, is the average number of coaches in sports clubs, which increased from 4.27 in 2014 to 4.57 in 2019 $(+7.0 \%)$ and the average number of qualified coaches in sports club which increased from 1.71 in 2014 to 2.06 in $2019(+20.5 \%)$. The policy of increasing the number of active qualified coaches can only succeed if there is positive balance between new qualified coaches and drop out of (qualified) coaches. It is observed with FICOMS that more coaches are engaging with coach education every year, leading to more coaches in sports clubs obtaining a coach qualification. In 2014 there were 1,254 sports clubs with at least one coach obtaining a new qualification; in 2019 , this number increased to 1,414 sports clubs $(+12.8 \%)$.

Case study 3 (CS3) with FICOMS revealed that the average drop out of coaches in 2019 is $20.6 \%$, where it peaked at more than $23 \%$ in 2016, so drop out is decreasing slowly (figure 6). During analysis of coach drop out, FICOMS made it possible to look at the profile of qualified vs. non-qualified coaches. In 2014, non-qualified coaches were on average 2 years older than qualified coaches (41.2 vs. 39.2 years old). In 2019, qualified coaches instead were on average 2 years older than non-qualified coaches (39.7 vs. 37.7 years old). As such, this is an indication that in the period between 2014 and 2019 more non-qualified coaches stopped coaching (drop out) than qualified. Gender differences reveal that female coaches are more than 9 years younger than male coaches ( 32.5 vs. 41.8 years old), there are less female 
qualified coaches $(28.1 \%)$ than female non-qualified coaches $(37.8 \%)$ and the drop out of female coaches is higher than for male coaches. The drop out of non-qualified coaches is significantly higher (26.1\% vs. $13.9 \%)$ than for qualified coaches, which is an important reason for the increase in the qualification ratio of our coaches in Flanders between 2014 $(40.3 \%)$ and $2019(45.2 \%)$.

Within this section, by means of three case studies, we have illustrated the early possibilities of FICOMS. By this we mean, how FICOMS can generate detailed appropriate insight which can be used for stakeholder action/intervention. For the first time, insight is available in relation to the throughput and output of our coach education system in Flanders. Consequently, it becomes possible to monitor the characteristics of all the coaches obtaining qualifications (CS1), if and which sports clubs are bridging the gap on qualified coaches (CS2) and monitor the evolution of the drop out of coaches (CS3).

\section{Limitations and future directions}

At the end of this article describing the possibilities and early insights of FICOMS, it is important to point out what we perceive to be the main limitations. The 'I' in FICOMS represents interactivity. Currently, data are shown in tables, graphs and maps where some interactivity is possible, but we wish to expand this with functionality to export data, print pdf reports, add tooltips and provide drill-through or zoom-in possibilities on specific data. This will represent necessary major improvements for researchers, sports federations, sports services at the municipalities and policymakers. At present, data is only obtained from coaches of the sports clubs linked with recognised sports federations. Information is missed on fitness clubs, some of the outdoor facilities and the non-organised sports sector. Additionally, it is not possible to monitor the amount of training hours for every coach and which athletes/teams are coached by which coach. Being able to do this would be beneficial 
because we can then calculate the proportion of training hours with qualified coaches in relation to the amount of training hours with non-qualified coaches.

Within this paper we have made the case that FICOMS is already a powerful tool and an essential instrument for policymakers, sports federations, sport services at the municipalities and researchers in Flanders. However, while we believe that this represents a significant story for monitoring and evaluation in coach education, plans exist to extend this work even further. At short notice, there is a desire to use FICOMS to monitor the impact of certain events (e.g. COVID-19) on coaches entering (input) our coach education system, the number of coaches obtaining qualifications (throughput) and on sports coaching in the sports clubs (output) in Flanders. FICOMS can be utilised for in-depth analysis, drawing conclusions and altering our coach education programmes where necessary, all in an agile and responsive manner. Further, FICOMS will be integrated with other data sources presented in figure 1, such as data on elite sport, sport at/after school, talent detection programmes, sport in nature, sport at work, etc. There is an intention to understand what the common characteristics are of people doing sport in an organised context (e.g. sports clubs) and in a non-organised sports context (e.g. at/after school, in nature, at work, etc.). By finding common characteristics, we can give policy advice to stimulate people transitioning from one context to another under supervision of coaches if applicable.

Next, there is an ambition to accelerate the process of importing new data on coaches in FICOMS to give sports federations, policy makers, researchers and sports services at the municipalities quicker insights in trends. At present, there is access to data of six consecutive years, but along with importing more years, a longer-term analysis can be done. This will make it possible to evolve FICOMS from a descriptive tool to a predictive or prescriptive tool using new methods like artificial intelligence, interactive correlation plots or regression analysis, etc. 

characteristics of coaches; for example, gender differences, qualification level and in the most popular sports, drop out of coaches.

\section{Conclusion}

Within the present article we have described why FICOMS has been developed and

438

439 how it has assisted Sport Vlaanderen (along with many other stakeholders) to understand the impact of the coach education system within VTS. By describing the main characteristics of FICOMS and the early insights by means of three case studies, we wanted to illustrate that the insights generated are not only useful in Flanders but have a huge potential for different stakeholders, such as governments, policymakers, sports federations, Olympic committees, education partners, municipalities and researchers. Nevertheless, there are some current limitations and considerations to be taken into account and these have been described. Within our future work we intend to share a much more detailed series of case studies similar to those considered with brevity above.

\section{(1)}




\section{References}

Callary, B., \& Gearity, B. (2019). Coach developer special issue: global perspectives in coach education for the coach developer. International Sport Coaching Journal, 6(3), 261262.

Campbell, S., \& Waller, S. (2020). Systematic Review of the Contemporary Research on Coach Development Programs. International Journal of Coaching Science, 14(1), 3-38. Ciampolini, V., Tozetto, A. V., Milan, F. J., Camiré, M., \& Milistetd, M. (2020).

Lifelong learning pathway of a coach developer operating in a national sport federation. International Journal of Sports Science \& Coaching, doi:

\section{$\underline{10.1177 / 1747954120912384}$}

Coopoo, Y., \& Morris-Eyton, H. F. (2014). Assessing the needs of coaches in developing a coach education framework. African Journal for Physical Health Education, Recreation and Dance, 20(1), 1-10.

Cushion, C. J., Armour, K. M., \& Jones, R. L. (2003). Coach Education and Continuing Professional Development: Experience and Learning to Coach. Quest, 55(3), 215230. doi: $\underline{10.1080 / 00336297.2003 .10491800}$

Cushman, G., Veal, A.J., \& Zuzanek, J. (2005). Free time and leisure participation: international perspectives. Wallingford: CABI Publishing, pp. 1-298.

Decré, H. (2019, February 22). Sportclubs massaal op zoek naar trainers: "Nood aan goede trainers is groot". VRT NWS. Retrieved from

\section{https://www.vrt.be/vrtnws/nl/2019/02/22/groot-tekort-aan-trainers-bij-sportclubs/}

Duffy, P., Hartley, H., Bales, J., Crespo, M., Dick, F., Vardhan, D., \& Curado, J. (2011). Sport coaching as a 'profession': challenges and future directions. International Journal of Coaching Science, 5(2). 
Erickson, K., Bruner, M. W., MacDonald, D. J., \& Côté, J. (2008). Gaining insight into actual and preferred sources of coaching knowledge. International Journal of Sports Science \& Coaching, 3(4), 527-538.

Estonian Foundation of Sports Education and Information. (2020). Eesti

Spordiregister. Retrieved from: https://www.spordiregister.ee/en/treener

European Commission. (2020). EU Work Plan for Sport (2017-2020) - Expert group on skills and human resources development in sport: Guidelines regarding the minimum requirements in skills and competences for coaches (February 2020). doi: 10.2766/69405 Eurostat. (2019). Retrieved from https://ec.europa.eu/eurostat/data/database Galatti, L., Bettega, O. B., Brasil, V. Z., de Souza Sobrinho, A. E. P., Bertram, R., Tozetto, A. V. B., Rodrigues, H.A., Collet, C., Nascimento, J., \& Milistetd, M. (2016). Coaching in Brazil sport coaching as a profession in Brazil: an analysis of the coaching literature in Brazil from 2000-2015. International Sport Coaching Journal, 3(3), 316-331.

Gratton, C., Rowe, N., \& Veal, A.J. (2011). International Comparisons of Sports participation in European Countries: an Update of the COMPASS Project. European Journal for Sport and Society, 8(1-2), 99-116.

Harris, K. (2018). Building sport for development practitioners' capacity for undertaking monitoring and evaluation-reflections on a training programme building capacity in realist evaluation. International Journal of Sport Policy and Politics, 10(4), 795-814. International Council for Coaching Excellence. (2013). The International Sport Coaching Framework Version 1.2 (pp. 1-60). Champaign: Human Kinetics. Lara-Bercial, S., North, J., Hämäläinen, K., Oltmanns, K., Minkhorst, J., \& Petrovic, L. (2017). European Sport Coaching Framework. Champaign: Human Kinetics, pp. 1-75. Le Bacq, T. (2019, September 9). Nog nooit zoveel volk in sportclub, nog nooit zo'n nood aan trainers. Het Nieuwsblad, p. 6. 
Mallett, C. J., Trudel, P., Lyle, J., \& Rynne, S. B. (2009). Formal vs. informal coach education. International Journal of Sports Science \& Coaching, 4(3), 325-364.

$$
\text { Milistetd, M., Ciampolini, V., Salles, W. D. N., Ramos, V., Galatti, L. R., \& }
$$

Nascimento, J. V. D. (2016). Coaches' development in Brazil: Structure of sports organizational programmes. Sports Coaching Review, 5(2), 138-152.

Morris-Eyton, H. F., \& Roux, C. J. (2019). Curriculum development in sport coach education within a South African context: a case study. South African Journal for Research in Sport, Physical Education and Recreation, 41(2), 87-96.

North, J. (2016). Benchmarking sport coach education and development. Advances in Coach Education and Development: From Research to Practice, 17.

Piggott, D. (2012). Coaches' experiences of formal coach education: a critical sociological investigation. Sport, Education and Society, 17(4), 535-554.

Santos, F., Camiré, M., MacDonald, D. J., Campos, H., Conceição, M., \& Silva, A. (2019). Process and outcome evaluation of a positive youth development-focused online coach education course. International Sport Coaching Journal, 6(1), 1-12.

Sports coach UK. (2009). The coaching workforce 2009-2016. Sports coach UK, Leeds, pp. 1-150.

Sport Vlaanderen. (2020). Data Warehouse Sport Vlaanderen. Retrieved from https://www.sport.vlaanderen/kennisplatform/

Stodter, A., \& Cushion, C. J. (2017). What works in coach learning, how, and for whom? A grounded process of soccer coaches' professional learning. Qualitative Research in Sport, Exercise and Health, 9(3), 321-338.

Vangrunderbeek, H. \& Ponnet, H. (2020). The History of Coach Education in Flanders. International Sport Coaching Journal, 7(3), 380-389. doi: 10.1123/iscj.2020-0049 
Papers published within ISCJ section 'Coaching in...' (2014-2020)

\begin{tabular}{|c|c|c|c|c|}
\hline $\mathbf{N}^{\circ}$ & Coaching in & Continent & Year \& Issue & Authors \\
\hline 1 & South Africa & Africa & $2014(1), 33-41$ & $\begin{array}{l}\text { Jerry Segwaba, Desiree Vardhan and Patrick } \\
\text { Duffy }\end{array}$ \\
\hline 2 & Singapore & Asia & $2014(2), 94-102$ & $\begin{array}{l}\text { Koon Teck Koh, Wenxiang Foo, Goken } \\
\text { Sakamoto and Adrian Low }\end{array}$ \\
\hline 3 & Brazil & $\begin{array}{l}\text { South- } \\
\text { America }\end{array}$ & $2014(3), 165-172$ & $\begin{array}{l}\text { Michel Milistetd, Pierre Trudel, Isabel } \\
\text { Mesquita and Juarez Vieira do Nascimento }\end{array}$ \\
\hline 4 & Poland & Europe & $2015(1), 50-63$ & $\begin{array}{l}\text { Ryszard Panfil, Marcin Krawczynski, Piotr } \\
\text { Marek and Lukasz Panfil }\end{array}$ \\
\hline 5 & Sweden & Europe & 2015 (2), 187-191 & Marie Hedberg \\
\hline 6 & New Zealand & Oceania & $2015(3), 330-338$ & Lynn Kidman and David Keelty \\
\hline 7 & Ireland & Europe & $2016(1), 65-74$ & Fiona Chambers and Robin Gregg \\
\hline 8 & Portugal & Europe & $2016(2), 178-183$ & $\begin{array}{l}\text { Rui Resende, Pedro Sequeira and Hugo } \\
\text { Sarmento }\end{array}$ \\
\hline 9 & Brazil & $\begin{array}{l}\text { South- } \\
\text { America }\end{array}$ & 2016 (3), 316-331 & $\begin{array}{l}\text { Larissa Galatti, Otavio Baggiotto } \\
\text { Bettega, Vinícius Zeilmann Brasil, Antonio } \\
\text { Evanhoé Pereira de Souza Sobrinho, Rachael } \\
\text { Bertram, et al. }\end{array}$ \\
\hline 10 & Finland & Europe & $2016(3), 332-343$ & Kirsi Hämäläinen and Minna Blomqvist \\
\hline 11 & Russia & Europe/Asia & $2017(1), 90-94$ & $\begin{array}{l}\text { Vladislav A. Bespomoshchnov and Leonid V. } \\
\text { Mikhno }\end{array}$ \\
\hline 12 & United States & $\begin{array}{l}\text { North- } \\
\text { America }\end{array}$ & 2017 (2), 220-234 & $\begin{array}{l}\text { Bradford Strand, Shannon David, Katie J. } \\
\text { Lyman and Jay M. Albrecht }\end{array}$ \\
\hline 13 & Mexico & $\begin{array}{l}\text { North- } \\
\text { America }\end{array}$ & $2017(3), 345-352$ & $\begin{array}{l}\text { Ciria Margarita Salazar C., Pedro Julian Flores } \\
\text { Moreno, José Encarnación Del Río } \\
\text { Valdivia, Lenin Tlamatini Barajas Pineda, Julio } \\
\text { Alejandro Gómez Figueroa and Martha Patricia } \\
\text { Pérez López }\end{array}$ \\
\hline 14 & Botswana & Africa & $2018(1), 79-83$ & Tshepang Tshube and Stephanie J. Hanrahan \\
\hline 15 & Ireland & Europe & $2018(2), 183-191$ & Niall O’Regan and Seamus Kelly \\
\hline 16 & Spain & Europe & $2018(3), 281-292$ & $\begin{array}{l}\text { Sebastián Feu, Javier García-Rubio, Antonio } \\
\text { Antúnez and Sergio Ibáñez }\end{array}$ \\
\hline 17 & Spain & Europe & $2019(1), 110-125$ & $\begin{array}{l}\text { Sergio J. Ibáñez, Javier García-Rubio, Antonio } \\
\text { Antúnez and Sebastián Feu }\end{array}$ \\
\hline 18 & United States & $\begin{array}{l}\text { North- } \\
\text { America }\end{array}$ & $2019(2), 220-225$ & $\begin{array}{l}\text { Lori A. Gano-Overway and Kristen } \\
\text { Dieffenbach }\end{array}$ \\
\hline 19 & Brazil & $\begin{array}{l}\text { South- } \\
\text { America }\end{array}$ & $2019(3), 339-348$ & $\begin{array}{l}\text { Larissa R. Galatti, Yura Yuka Sato dos } \\
\text { Santos and Paula Korsakas }\end{array}$ \\
\hline 20 & Brazil & $\begin{array}{l}\text { South- } \\
\text { America }\end{array}$ & $2020(1), 82-88$ & $\begin{array}{l}\text { Patricia Gaion, Michel Milistetd, Fernando } \\
\text { Santos, Andressa Contreira, Luciane } \\
\text { Arantes and Nayara Caruzzo }\end{array}$ \\
\hline 21 & United States & $\begin{array}{l}\text { North- } \\
\text { America }\end{array}$ & $2020(1), 89-94$ & $\begin{array}{l}\text { Lori Gano-Overway, Pete Van } \\
\text { Mullem, Melissa Long, Melissa } \\
\text { Thompson, Bob Benham, et al. }\end{array}$ \\
\hline 22 & United States & $\begin{array}{l}\text { North- } \\
\text { America }\end{array}$ & $2020(2), 239-251$ & $\begin{array}{l}\text { Bradley Fawver, Garrett F. Beatty, John T. } \\
\text { Roman and Kevin Kurtz }\end{array}$ \\
\hline 23 & Belgium & Europe & $2020(3), 380-389$ & Hans Vangrunderbeek and Hans Ponnet \\
\hline
\end{tabular}


535

536

\section{Figure 1}

Database structure behind FICOMS

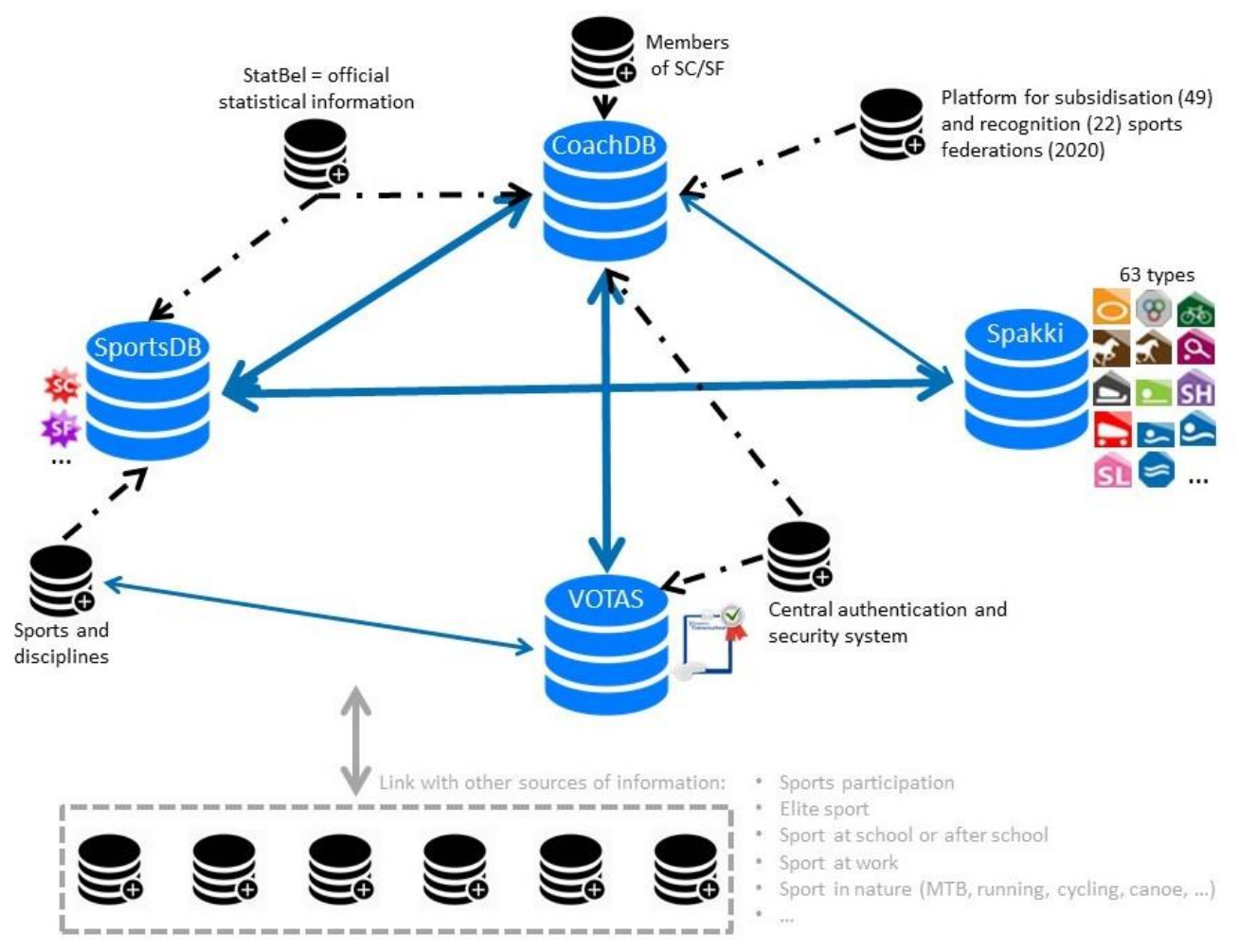

538

539

Figure 2

540

From data to visualisation

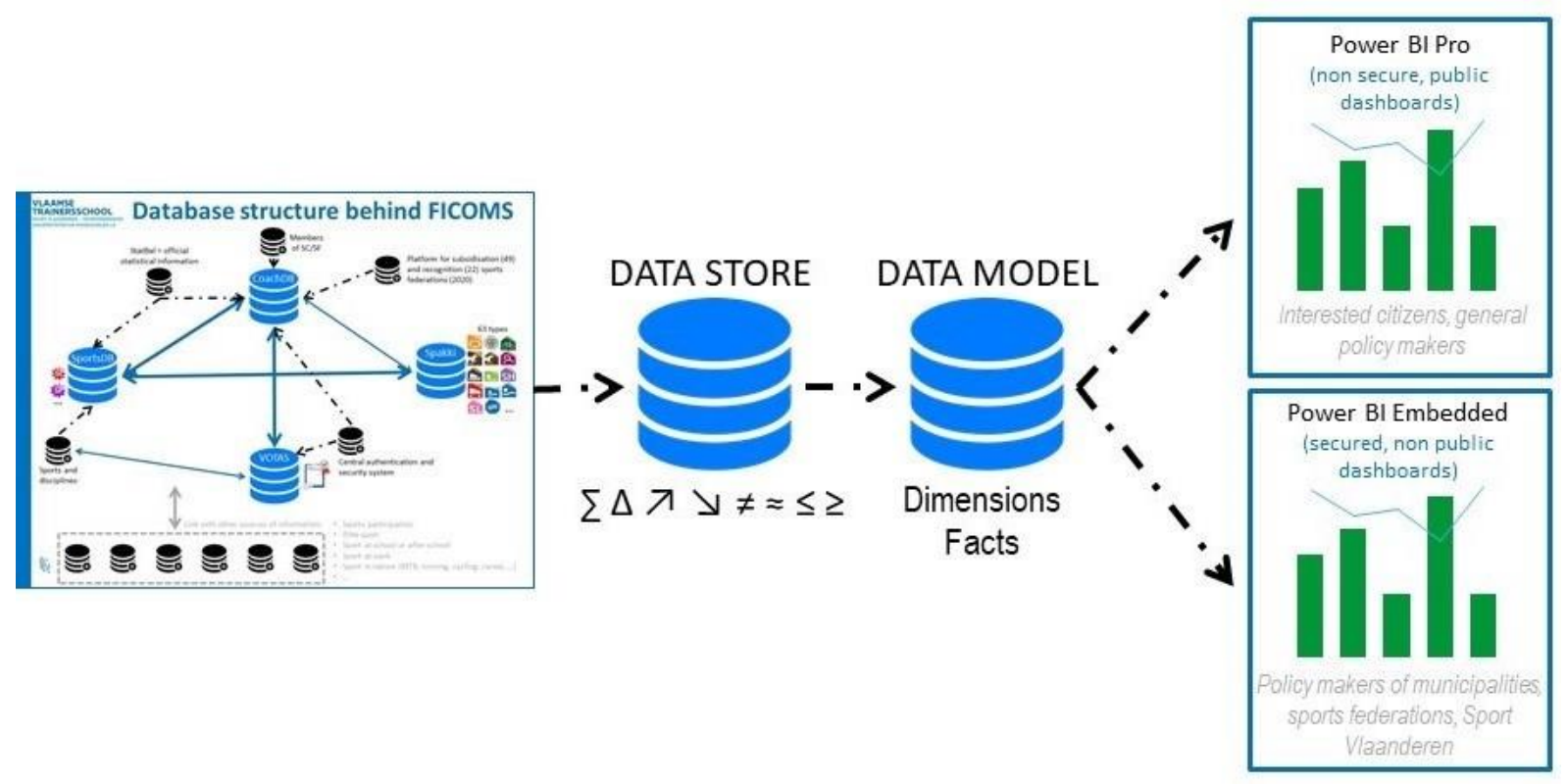


Figure 3

\section{FICOMS}

\begin{tabular}{|c|c|c|}
\hline $\begin{array}{l}\text { INPUT } \\
\text { Coaches entering coach } \\
\text { education programmes }\end{array}$ & $\begin{array}{l}\text { THROUGHPUT } \\
\text { coaches obtaining a qualification } \\
\text { through coach education }\end{array}$ & $\begin{array}{l}\text { OUTPUT } \\
\text { Active coaches in the sports } \\
\text { clubs }\end{array}$ \\
\hline $\begin{array}{l}\text { Coaches starting a coach education } \\
\text { programme: } \\
\text { - Background } \\
\text { - Sport } \\
\text { - Sports club } \\
\text { - Sports federation } \\
\text { - Age } \\
\text { - Render } \\
\text { - Pridence } \\
\text { - PE-backgrous qualifications } \\
\text { - Which pathways for coach education } \\
\text { (Vangrunderbeek \& Ponnet, 2020) } \\
\text { - Regular course } \\
\text { - Recognition of Prior Learning } \\
\text { - Assimilation of foreign } \\
\text { - qualification } \\
\text { (Former) elite athlete }\end{array}$ & $\begin{array}{l}\text { - Characteristics of coach education } \\
\text { programmes } \\
\text { - Modules, items, hours } \\
\text { - Benchmarking with other } \\
\text { sports, with other countries } \\
\text { - Success ratios of coach } \\
\text { education programmes } \\
\text { - Characteristics of coach developers } \\
\text { - Holistic Quality Control (HQC) } \\
\text { - Courses } \\
\text { - Coach developers } \\
\text { - Exams } \\
\text { - Obtained qualifications } \\
\text { - How many? } \\
\text { - Trends/Differences in age, } \\
\text { gender, regions, sports } \\
\text { - Trends over time } \\
\text { - Trends in pathways }\end{array}$ & $\begin{array}{l}\text { - Characteristics } \\
\text { - How many? Is there a lack? } \\
\text { - Trends/Diffed vonences in age, } \\
\text { gender, regions, sports, sports } \\
\text { federations } \\
\text { - PE-qualifications of coaches } \\
\text { - Trends over time } \\
\text { - Trend in number of qualified } \\
\text { coaches (+ qualification \%) } \\
\text { - Trend in number of sports } \\
\text { clubs with > } 1 \text { qualified coach } \\
\text { - Trend in new coaches (after } \\
\text { obtaining qualification) } \\
\text { - Trend in drop-out of active } \\
\text { coaches } \\
\text { Correlation studies } \\
\text { - Drop-out coaches vs. } \\
\text { qualification level } \\
\text { - Drop-out coaches vs. size of } \\
\text { sports club/sports federation } \\
\text { Drop-out coaches vs. drop-out } \\
\text { of sports participants }\end{array}$ \\
\hline
\end{tabular}

Figure 4

Total: 6.028 coaches obtained a qualification in 2019 (average success rate $=86 \%$; age $=30$ years; male $=64 \%$ )

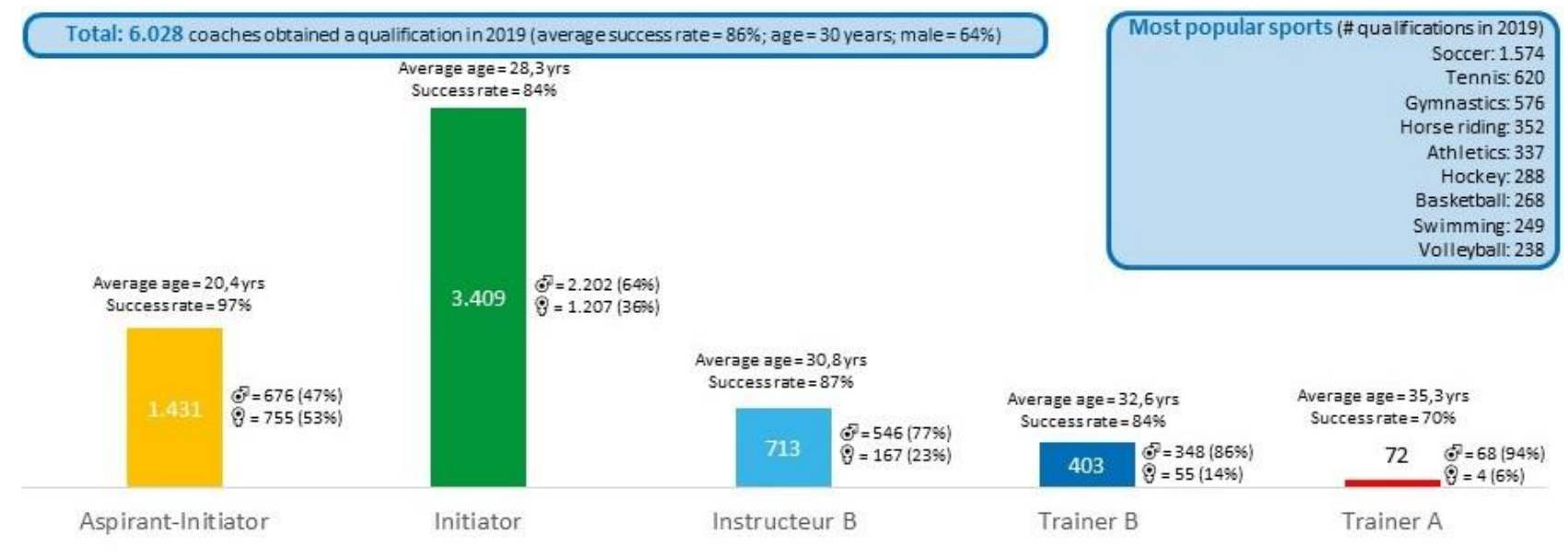


Figure 5

551 FICOMS dashboard on active, qualified and non-qualified, coaches operating in sports clubs

552 (2014-2019)

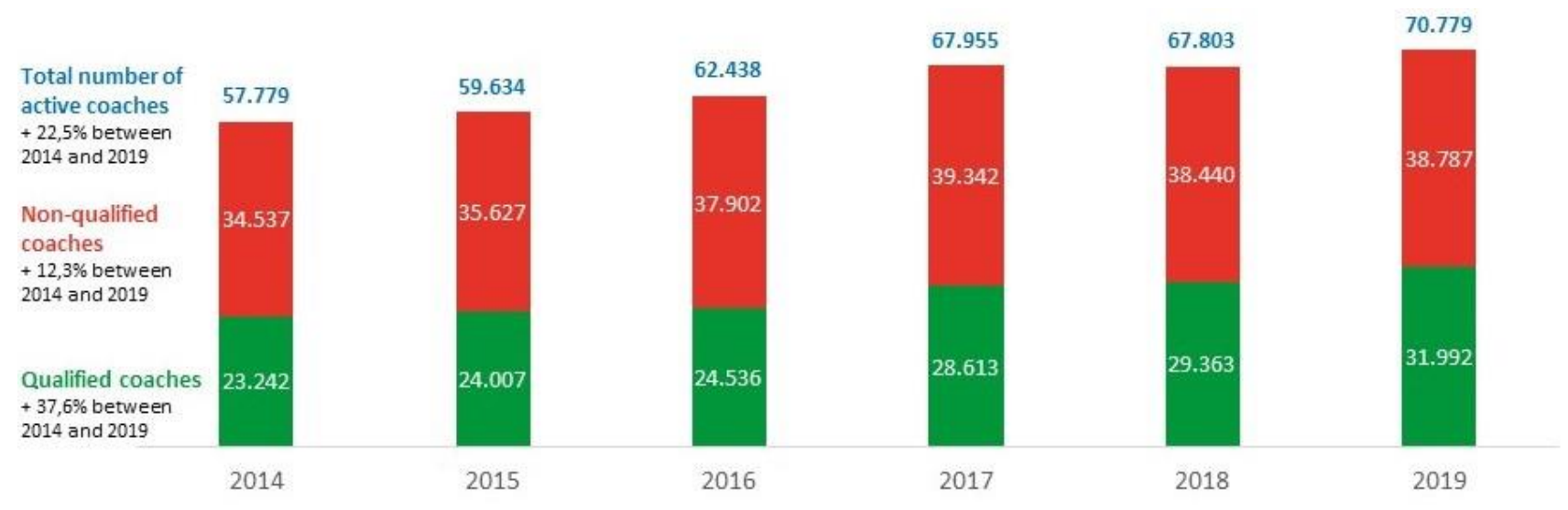

554

555 Figure 6

556 FICOMS dashboard on average drop out of qualified vs. non-qualified; male vs. female

557 coaches (2014-2019)

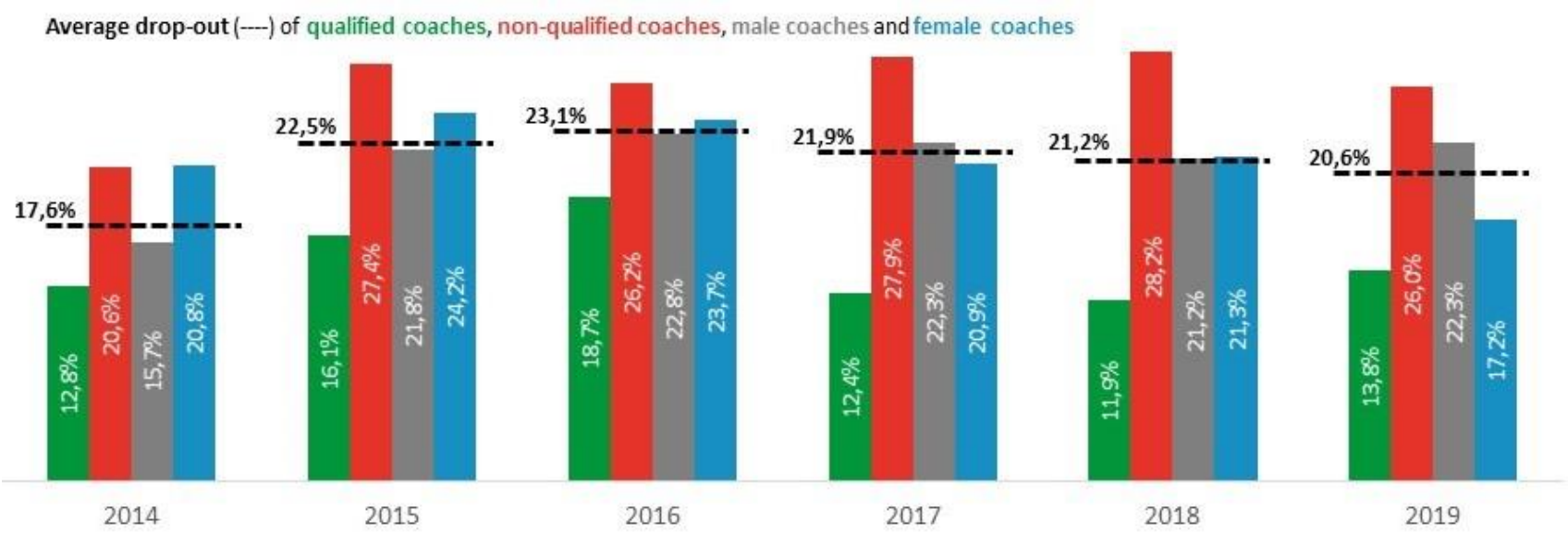

